

\subsection{Meteorología y predicción probabilista en la sociedad}

\author{
Berta Burguete Ors \\ Antropóloga y Filósofa \\ Carlos Santos Burguete \\ CNP, Agencia Estatal de Meteorología (AEMET)
}

\subsubsection{Observabilidad e importancia del tiempo en la sociedad}

Al contrario que algunos objetos de observación científica, los fenómenos meteorológicos son accesibles a todas las personas: mientras los agujeros negros o los elementos que recorren raudos los aceleradores de partículas no están al alcance del público general, la lluvia, el viento o la temperatura son observables por todo el mundo, lo que podría producir la falsa impresión de que, sobre la base de la experiencia cotidiana, cualquiera está en disposición de discernir la veracidad científica de unos pronósticos de enorme complejidad. Este fenómeno, que consiste en que nuestra ignorancia en un campo nos lleva a creer que sabemos lo suficiente sobre él, es conocido como Síndrome Dunning-Kruger [10].

Por otro lado, el tiempo está muy presente en la sociedad del riesgo en la que vivimos [2]: evitar posibles peligros, por pequeños que sean, cobra una importancia central en nuestra realidad.

Así, las predicciones de potencial riesgo meteorológico no son en absoluto neutras: las expectativas que crean, generan una gran cantidad de decisiones de muy diferentes calibres, desde la prevención de amenazas tan graves como las inundaciones o las condiciones atmosféricas en las que volará un avión, pasando por cuestiones económicas que afectan a la industria turística, hasta cuestiones tan livianas como la elección de actividades de ocio o la indumentaria a vestir en un determinado día.

\subsubsection{Sesgo cognitivo y complejidad de los fenómenos meteorológicos}

Es común la errónea creencia de que los fenómenos físicos, por su carácter objetivo (una gota de lluvia es una gota de lluvia, quince grados son quince grados), se encuentran libres de interpretación por parte del sujeto que las percibe. Sin embargo, la filosofía, desde sus más ancianos inicios se ha preguntado cuánto (y cómo) podemos conocer, porque lo cierto es que nuestra percepción del mundo está altamente contaminada por lo que en la actualidad se conoce como sesgo cognitivo.

Por otra parte, los fenómenos meteorológicos presentan una complejidad asombrosa; las variaciones que sufre, por ejemplo, la temperatura o que experimenta el cielo en apenas un puñado de horas y en un radio muy corto de distancia, son notables. Esta variabilidad, no solo hace materialmente imposible resumir en pocas palabras algo que ha sido tan diferente en un marco de tiempo y espacio relativamente pequeños, sino que, además, su naturaleza volátil y carácter caótico obligan a presentar las predicciones en forma de probabilidades. La tendencia humana al ahorro cognitivo, es decir, a generalizar y presentar las verdades de la forma más simple posible, hace que el público ofrezca resistencia a las presentaciones de probabilidades: una predicción determinista (hoy lloverá) será mucho más digerible que una predicción probabilista (hay un cinco por ciento de posibilidades de que hoy llueva) y por ello, parece conferirle un carácter adivinatorio, casi fuera del rango científico. ¿Quién no ha dicho o escuchado alguna vez: «los del tiempo no han acertado hoy»?

Por si esto fuera poco, a menudo, la descripción de los fenómenos atmosféricos va acompañada de adjetivos calificativos cargados de gran subjetividad: Hace bueno/malo; hace frío/calor.

A la economía cognitiva (o generalización), es necesario sumarle el peso de la experiencia vital del observador en su interpretación o descripción del tiempo que ha hecho en un determinado día. Es un aspecto de uno de los sesgos cognitivos que enturbian nuestra percepción del mundo: el marco de la experiencia, una tesis que fue inicialmente planteada en los años setenta por ERWIN GOFFMAN [6], que incluso menciona específicamente la predicción meteorológica como generadora de decisiones, e inscrita en un marco social.

Interpretamos la realidad dentro del marco de nuestra experiencia. De forma que, un individuo que ha crecido en el norte de Noruega, considerará erróneo el pronóstico de lluvia para un día de agosto en Madrid si este se culmina con una precipitación leve, mientras que un individuo de una ciudad andaluza, lo considerará acertado. Las expectativas de ambos sobre la misma predicción diferirán de forma considerable y 
generarán diferentes decisiones. El noruego, por ejemplo, raramente cancelará sus planes de asistir a una sesión de cine al aire libre, a pesar de que se prevean precipitaciones, mientras que será más probable que el español se decante por otra actividad en el mismo caso.

No solo nuestra experiencia vivida nos hace interpretar una información de una manera u otra, sino también el modo en que ésta nos es presentada genera en nosotros distintas respuestas. La psicología cognitiva, así como la sociología y la teoría de la comunicación, se han ocupado del llamado efecto de encuadre (framing effect) [8]. En el efecto de encuadre, un caso particular de sesgo cognitivo, las personas reaccionan de forma diferente frente a una elección dependiendo de cómo se presenta ésta. El encuadre engloba los esquemas de interpretación del ser humano para entender los eventos, darles sentido y responder adecuadamente a ellos, lo que conlleva una toma de decisiones. Estos esquemas se van construyendo en el proceso de aprendizaje con pautas y filtros tanto racionales como emocionales. Un ejemplo sencillo es la forma de transmitir información médica sobre las probabilidades de supervivencia: no es lo mismo decir si no se toma la medicación tiene usted un $35 \%$ de probabilidades de morir que decir «si se toma esta medicación tiene usted un $65 \%$ de probabilidades de sobrevivir»; aunque la información subyacente pueda ser la misma, la reacción emocional del paciente es bien distinta. Otro ejemplo: «se consiguieron salvar 32 vidas» $\mathrm{o}$ «se perdieron 211 vidas en el accidente aéreo». Digamos que la forma importa tanto como el fondo. Para la gente suele ser más motivante una pérdida que la ganancia equivalente, una ganancia segura puede más que una probabilidad de la misma y se prefiere una probabilidad de pérdida que una pérdida segura. Las propagandas electorales, por ejemplo, suelen manipularse mediante efecto de encuadre.

Al igual que sucede en medicina, en meteorología la forma de transmitir la información es crucial. En medicina, por ejemplo, en casos críticos es fundamental brindar la información de forma delicada y estadísticamente consistente, lo que obliga a los profesionales correspondientes a tener una formación específica. En meteorología la forma de presentar y transmitir la información meteorológica plantea, en este contexto, un problema específico [5]. Así mismo, se ha señalado [7] la importancia para los comunicadores meteorológicos de comprender la psicología del usuario final, considerando el significado de la predicción pero también cómo el usuario la «escucha».

\subsubsection{La ciencia, la probabilidad y la pre- dicción probabilista en la sociedad}

¿Cómo percibe la opinión pública la ciencia y la tecnología, así como su propia formación científica? El Centro de Investigaciones Sociológicas (CIS) en su estudio 2652 Percepción social de la ciencia y la tecnología, de 2006, explora este asunto [3] con profundidad y detalle. Entre otras conclusiones, se desvela que, con respecto a los temas científicos y tecnológicos, la población española se siente informada pero muestra un interés relativamente bajo, principalmente por que considera estos temas como complicados. Además, se encuentra en general poco satisfecha con su nivel de formación en ciencia y técnica, empeorando la utilidad percibida con respecto a anteriores encuestas.

Centrando nuestra atención en la probabilidad como parte de la ciencia, la probabilidad es un modelo matemático de la realidad que permite abordar la descripción de ciertos fenómenos y la solución de algunos problemas de un modo elegante y eficaz. Cuando se profundiza en sus concepciones y se conoce mejor, entonces podemos decir incluso que la probabilidad es una teoría bastante honesta. La estadística, como subconjunto o aplicación de la probabilidad es una potente herramienta con un gran potencial de aplicación, pero necesita utilizarse apropiadamente y sus resultados interpretados adecuadamente porque, de lo contrario, puede ser la ciencia que dice que si tú tienes dos coches y yo ninguno entonces tenemos un coche cada uno. La información científica cuantitativa suele dar medidas acompañadas de su correspondiente incertidumbre, expresada a menudo en términos probabilistas o estadísticos. La probabilidad y la estadística forman parte de la formación científica básica.

Sin embargo, el lenguaje de los partes meteorológicos tradicionales es determinista: «llueve o no llueve», etc. Durante los primeros años de andadura de los sistema(s) de predicción por conjuntos (SPC), y aún hoy, a menudo la información probabilista que ofrecen se simplifica o traduce a un lenguaje determinista. En los países donde se ha conseguido implantar el uso de predicción probabilista, se ha podido comprobar el éxito de esta información para la toma de decisiones, especialmente en situaciones de riesgo. En EE. UU. desde 1965 el National Weather Service (NWS) proporciona predicciones probabilistas. Según MURPHY [5], dos de cada tres personas del público general preferían la información probabilista a la determinista. 


\subsubsection{Estudio del CIS sobre percepción de la meteorología}

Estos aspectos se ponen de manifiesto en el estudio que llevó a cabo en 2011 el Centro de Investigaciones Sociológicas (CIS), en colaboración con otros sociólogos y a demanda de AEMET, titulado Percepción de la meteorología [4] (http://analisis.cis.es/ cisdb . j sp?ESTUDIO=2886 última consulta septiembre 2017). El estudio abordaba una serie de cuestiones, entre otras:

- Frecuencia con la que se informa de diversos temas: deportes, meteorología, cultura, economía, política y tráfico, en contraste con la frecuencia con la que se informa sobre el tiempo meteorológico.

- Importancia de la información meteorológica en la sociedad.

- Escala de confianza en la información meteorológica.

- Valoración de la información meteorológica en diversos aspectos actualmente o en comparación con los últimos 10 años: acertada en las predicciones, clara y comprensible, y útil para la gente.

- Fiabilidad de las predicciones meteorológicas: para el mismo día, para el día siguiente, para tres días y para una semana.

- Frecuencia en el uso de la información meteorológica para diversas actividades: qué ropa ponerse, actividades al aire libre y sociales, trayectos diarios,...

- Fenómenos meteorológicos de mayor interés en los últimos 12 meses y aspectos personales a los que ha afectado.

- Influencia de una predicción meteorológica desacertada en los últimos 12 meses y aspectos personales a los que ha afectado.

- Importancia de diversos aspectos de la información meteorológica: el tipo, la probabilidad, el momento del día y el lugar de la precipitación, la temperatura máxima y mínima, la velocidad y la dirección del viento, la nubosidad y la sensación térmica.

- Comprensión de la información meteorológica.

- Valoración de los conocimientos sobre meteorología.

- Conocimiento sobre la predicción meteorológica (\% de probabilidad de lluvia).

- Preferencia por la forma de expresar la información sobre la temperatura.
- Riesgos meteorológicos que pueden afectar al entrevistado/a.

- Conocimiento de algún potencial peligro meteorológico (aviso o alerta). Medio a través del cual lo ha conocido. Páginas de internet que consulta para informarse. Medidas tomadas. Valoración de la declaración de la existencia del potencial peligro meteorológico.

- Conocimiento del Plan Meteoalerta y del sistema de colores para el aviso de algún potencial peligro meteorológico (aviso o alerta). Importancia de un potencial peligro meteorológico (aviso o alerta) en color naranja.

- Conocimiento de los organismos que elaboran la información meteorológica y de AEMET. Medio a través del cual conoce AEMET.

- Escala de valoración de diversos servicios que presta la AEMET: acierto en las predicciones, objetividad y neutralidad, calidad de la información,... Y su evolución en los últimos 10 años.

Seleccionamos aquí tres preguntas del estudio, relevantes para este capítulo por estar relacionadas directamente con la probabilidad, la incertidumbre y la formación básica en meteorología, Figuras 40.1, 40.2 y 40.3 en la página 620. La primera pregunta (Figura 40.1) tiene que ver con la comprensión de una predicción de probabilidad de precipitación. La diversidad de las respuestas es notable y, aunque estas pueden reflejar poca cultura científica, también pueden denotar la falta de información o la ambigüedad de la misma. En el estudio de Crespo y col. [5] se señala la ambigüedad de la propia información que se provee, que no explicita la clase de sucesos a los que se hace referencia. Cuando se dice, por ejemplo, que hay un $30 \%$ de probabilidades de lluvia para mañana, esto no se puede entender si no se especifica a qué hace referencia ese $30 \%$ (tiempo, región o días similares). Este es un aspecto a tener en cuenta por los proveedores de información meteorológica, aunque no resulta sencillo. La segunda pregunta (Figura 40.2) está relacionada con la incertidumbre, y revela que el público general no se siente incómodo con incertidumbres presentadas de forma clara: temperatura máxima entre 23 y 25 grados, en vez de presentar el tradicional 24 grados exactos. La última pregunta (Figura 40.3), relacionada con el grado de percepción de la propia formación meteorológica necesaria para la vida cotidiana, muestra que la mayoría está satisfecha con lo que sabe sobre meteorología. 


\section{PREGUNTA 14}

Suponga que en la predicción meteorológica de mañana se dice que 'hay un $60 \%$ de probabilidad de lluvia'.

¿Cuál de las frases siguientes cree Ud. que describe mejor lo que esto significa?

\begin{tabular}{lll}
\hline Pregunta & \% & (N) \\
\hline Lloverá mañana en el 60\% del lugar de la predicción & 21.2 & $(628)$ \\
Lloverá mañana el 60\% del tiempo & 12.4 & $(366)$ \\
De cada 100 días con las características similares & 19.1 & $(565)$ \\
a mañana, lloverá en 60 & 13.3 & $(393)$ \\
El 60\% de los/as meteorólogos/as cree que lloverá mañana & 13.2 & $(390)$ \\
Otras respuestas & 1.1 & $(32)$ \\
Ninguna & 17.9 & $(528)$ \\
N.S. & 1.8 & $(53)$ \\
N.C. & 100.0 & $(2958)$ \\
TOTAL & & 1
\end{tabular}

Figura 40.1: Pregunta, relacionada con la probabilidad de lluvia, seleccionada del estudio del Centro de Investigaciones Sociológicas (CIS) Percepción de la meteorología de 2011 [4]. La diversidad de las respuestas es notable y éstas muestran que la probabilidad es todavía un terreno resbaladizo.

PREGUNTA 15

A Ud. le pueden informar sobre la temperatura diciendo que mañana 'la temperatura máxima alcanzará los $24^{\circ}$ ' o bien que 'la temperatura máxima oscilará entre $23^{\circ}$ y $25^{\circ}$. ¿De cuál de las dos formas prefiere que se le informe?

\begin{tabular}{lll}
\hline Pregunta & \% & $(\mathrm{N})$ \\
\hline La temperatura máxima alcanzará los 240 & 28.0 & $(827)$ \\
La temperatura máxima oscilará entre 230 y 250 & 44.1 & $(1304)$ \\
Cualquiera de las dos & 25.1 & $(741)$ \\
Ninguna & 0.8 & $(24)$ \\
N.S. & 1.8 & $(52)$ \\
N.C. & 0.3 & $(8)$ \\
TOTAL & $100.0(2958)$
\end{tabular}

Figura 40.2: Pregunta, como en la Figura 40.1, en este caso relacionada con la incertidumbre en una información meteorológica muy concreta: la temperatura máxima. El público no parece demasiado incómodo con una incertidumbre de \pm 1 grado: sólo un $28 \%$ elige el dato exacto, mientras que un $44 \%$ elige la incertidumbre y un $25 \%$ está cómodo con ambas opciones. 
PREGUNTA 13

Lo que Ud. sabe sobre meteorología, ¿es suficiente para lo que Ud. necesita, o por el contrario es insuficiente y cree que necesitaría saber más?

\begin{tabular}{lll}
\hline Pregunta & $\%$ & (N) \\
\hline Suficiente para lo que necesita & 88.8 & $(2626)$ \\
Insuficiente, necesitaría saber más & 9.7 & $(287)$ \\
N.S. & 1.1 & $(32)$ \\
N.C. & 0.4 & $(11)$ \\
TOTAL & 100.0 & $(2958)$
\end{tabular}

Figura 40.3: Pregunta, como en la Figura 40.1, en este caso relacionada con la percepción personal de los propios conocimientos meteorológicos necesarios: una mayoría piensa que son suficientes. 


\subsection{El reto probabilista en los me- dios de comunicación}

\author{
JosÉ Miguel ViñaS \\ DIVULGAMETEO \\ Consultor OMM
}

A mediados de los años 90 del siglo pasado, comencé mi andadura como comunicador y divulgador de la Meteorología en España. Una de las facetas de mi trabajo ha sido y sigue siendo la elaboración de pronósticos meteorológicos y su difusión a través de los medios de comunicación en los que desarrollo mi actividad profesional. He tocado todos los palos; desde la prensa escrita, la televisión y la radio, hasta Internet en sus múltiples plataformas (foros, blogs, redes sociales...), y dicha circunstancia me ha permitido ir aprendiendo a adaptar convenientemente el mensaje y el formato (contenido y continente) a cada uno de los medios. En cualquiera de ellos nunca han faltado en mis predicciones los términos probabilistas. Hablar de posibilidad de lluvias débiles en el Cantábrico oriental o de que serán probables las tormentas por la tarde en el Pirineo catalán y al sur del sistema Ibérico, no es algo novedoso en el repertorio de expresiones que usamos con asiduidad los comunicadores del tiempo. Siempre se ha hecho así, en mayor o menor medida, aunque empleándose esa terminología de una forma más cualitativa que cuantitativa.

Mis inicios como comunicador meteorológico coinciden casi en el tiempo con el desarrollo de las predicciones por conjuntos (SPC o EPS) por parte del European Centre for Medium-range Weather Forecasts -Centro Europeo de Predicción a Plazo Medio- (ECMWF). A partir de ese momento -año 1992- se empezó a tener la capacidad de acotar la incertidumbre inherente a la predicción de los estados futuros de la atmósfera. Ha pasado ya un cuarto de siglo desde ese importante hito en la historia de la predicción numérica del tiempo, a pesar de lo cual, los comunicadores seguimos ofreciendo pronósticos deterministas y transmitiendo «certezas» a los destinatarios de la información, matizadas, a veces, por «posibles» $\mathrm{y}$ «probables», que en muchos casos son meras coletillas. De forma muy tímida, en los últimos años las predicciones probabilistas se han ido incorporando a nuestro discurso, aunque su integración todavía dista mucho de ser completa. En mi opinión -compartida por mucha gente, aunque no por todo el colectivo de meteorólogos y comunicadores- ofrecer distintos escenarios futuros, con datos de probabilidad asociados a cada uno de ellos, es la mejor información que puede ofrecerse a los ciudadanos, y ese debe ser el objetivo a alcanzar, buscando para ello las fórmulas adecuadas. Este es, para mí, el principal reto de la comunicación meteorológica en la actualidad: el reto probabilista.

Hay varias razones que explican esa pasmosa lentitud con la que las predicciones probabilistas han ido apareciendo en los medios de comunicación, en la mayoría de los casos con cuentagotas y más como un experimento para ver qué pasa, que como una implementación efectiva de las mismas. La principal razón reside en el hecho de que la mayoría de los productos probabilistas desarrollados por el ECMWF son de pago, con acceso restringido. Se trata de algo difícil de entender. No tiene sentido que se hayan desarrollado unos productos destinados a mejorar sensiblemente la información meteorológica -invirtiendo en ello mucho dinero de las arcas públicas y recursos humanos-, y que no se permita el acceso libre a los mismos, lo que garantizaría su difusión, beneficiándose de ello toda la sociedad. La situación es tan absurda como si el inventor de la rueda no hubiera compartido su invento con sus congéneres y la hubiera mantenido oculta en una gruta.

En la actualidad, los comunicadores del tiempo ofrecemos en los medios unos buenos pronósticos a cortomedio plazo, algo que valoran positivamente las personas que los consultan (los usuarios de la información meteorológica). Ocho de cada diez personas consideran que las predicciones son muy o bastante acertadas, y nueve de cada diez manifiestan que las comprenden y las consideran útiles [5]. No obstante, su calidad y valor podrían mejorar aún más si pudiéramos echar mano de los productos probabilistas, particularmente útiles bajo situaciones de baja predecibilidad y en determinados momentos del año en los que gran parte de la población está muy atenta al pronóstico del tiempo (la Semana Santa es el ejemplo más ilustrativo). La implementación de las predicciones probabilistas diluiría la idea del acierto/fallo en el pronóstico, muy arraigada aún en la sociedad, y la convertiría en algo parecido a un grado de acierto y de utilidad.

Otra de las razones que se suele argumentar como freno a la difusión de las predicciones probabilistas en los medios, es la dificultad que tiene la población para interpretar correctamente una información en términos de probabilidades. Sobre este tema se han hecho algunos estudios sociológicos (basados en encuestas, ver en otro apartado de este capítulo) que han arrojado algunas pistas, pero que no han llegado a nada 
concluyente y definitivo. Asignar un determinado valor porcentual a la probabilidad de que llueva en un lugar no es algo que, a priori, deba interpretarse peor que el diagnóstico de un médico, cuando le indica al paciente cuáles son las probabilidades de éxito de una operación quirúrgica o de una quimioterapia. La gente empieza a estar familiarizada con el lenguaje meteorológico probabilista, gracias a las aplicaciones de móvil. El $75 \%$ de la población tiene un smartphone [1]. La gente sabe diferenciar bien entre un 20, un 60 o un $80 \%$. En el caso particular de la predicción probabilista, un alto porcentaje es sinónimo de baja incertidumbre y viceversa. Cualquier persona a la que se le advierta de que hay un $80 \%$ de probabilidad de que llueva con intensidad y de forma persistente el domingo, lo más seguro es que no planifique una excursión al aire libre para ese día. Por parte de los comunicadores es más honesto -y ajustado a la verdad científica- proporcionar esa información que afirmar categóricamente que la jornada dominical caerán chuzos de punta.

Es cierto que desde hace muchos años el comunicador del tiempo viene utilizando un discurso categórico al ofrecer el pronóstico, y así se ha educado al usuario de la información meteorológica. Pero no es menos cierto que, para mejorar su calidad y valor, se puede ir cambiando el lenguaje de las predicciones, sin que ese proceso sea traumático. Lo primero que hay que hacer es transmitir a la población la idea de que toda predicción lleva asociada una incertidumbre, para, a continuación, indicar que hoy en día tenemos la posibilidad de cuantificar dicha incertidumbre y de ofrecer dicha información. El espectacular desarrollo que ha tenido la supercomputación nos permite disponer de predicciones probabilistas. Al principio, los comunicadores nos vamos a encontrar con una resistencia. Esto es algo que tenemos que asumir. En la actualidad, la mayoría de los usuarios prefiere las predicciones categóricas (deterministas), ya que se ha estado nutriendo de ellas y son a las que se han acostumbrado. Si conseguimos vencer esa lógica resistencia, el viento soplará a nuestro favor y ganaremos todos.

Cada medio de comunicación requerirá, eso sí, de una determinada forma de transmitir las predicciones probabilistas. Fuera de España encontramos ya algunos ejemplos en los que se han implantado con éxito. Quizás uno de los más destacados sea el de los conos de probabilidad de las trayectorias de los ciclones tropicales, que muestran en muchas cadenas de televisión y que son fáciles de interpretar, muy intuitivos (Figura 40.4).

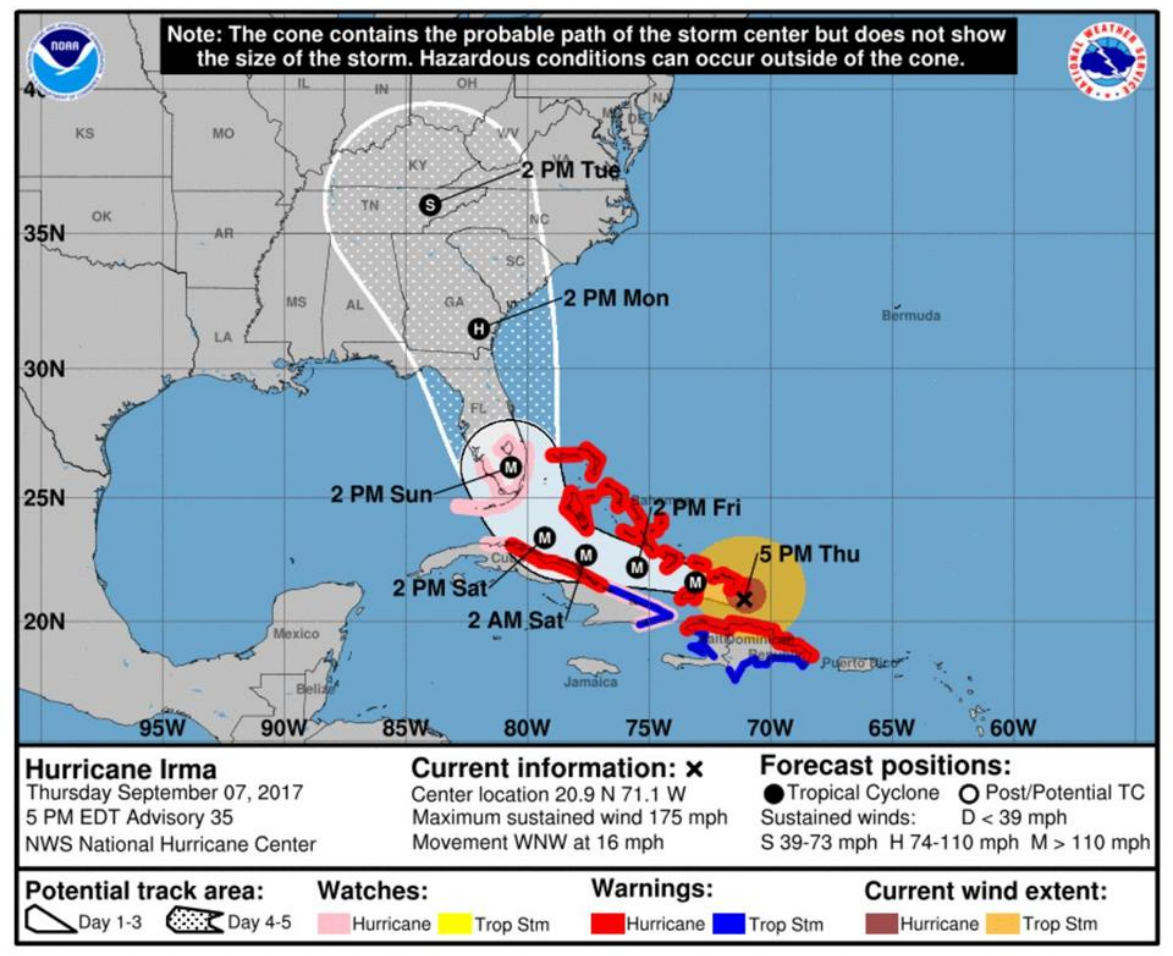

Figura 40.4: Conos de probabilidad del ciclón tropical Irma, septiembre de 2017. NHC. 
En la BBC también llevan tiempo ofreciendo interesantes pronósticos por conjuntos con las posibles trayectorias de profundas borrascas que se acercan a veces a las islas británicas. La fuente de esa información es la Met Office (Servicio Meteorológico del Reino Unido), que a través de su página web y en redes sociales también comparte ese tipo de mapas, de gran riqueza informativa. Se suelen mostrar tres posibles escenarios (el más probable, uno de probabilidad intermedia y el menos probable), con las principales incidencias meteorológicas en cada caso, localizadas en distintas áreas geográficas. Aquí en nuestro país sería un buen modelo a seguir, ya que cuando asoma por el Atlántico una de esas erráticas borrascas que periódicamente nos afectan, se podrían mostrar al telespectador varias posibles evoluciones futuras, cada una de ellas con su probabilidad de ocurrencia asociada. Hoy en día, se ofrece un único pronóstico determinista (el típico mapa de símbolos, en el caso de la televisión), no ofreciéndose al usuario otros posibles escenarios menos probables, pero que también son posibles y que podrían, en alguna ocasión puntual, dar tiempo adverso.

La radio, que es el medio en el que tengo una mayor experiencia, tiene la dificultad añadida de no poder mostrar información gráfica, lo que exige la búsqueda de fórmulas alternativas. Una de ellas consiste básicamente en describir a los oyentes lo que nos están mostrando los productos probabilistas. Esto exige un importante ejercicio de síntesis, ya que la información de un EPSgrama o meteograma (sec. 27.8.1 en la página 425) o de unos supergrupos (sec. 27.4.2 en la página 409) es significativamente mayor que la que contiene una predicción determinista al uso. Para poder abordar esa tarea, debemos de hacer un ejercicio previo de selección de la información que más nos interesa contar, la que sea más relevante desde el punto de vista informativo. Este análisis previo forma parte de la labor que debe llevar a cabo el comunicador radiofónico. Habrá veces en que tendremos que comentar un posible escenario, a pesar de su baja probabilidad, por la incidencia que, de producirse, pueda tener en la población. Pensemos, por ejemplo, en un entorno tormentoso previsto, en el que puedan darse los ingredientes adecuados para la formación de un peligroso sistema supercelular. Tales sistemas tormentosos son de mayor tamaño y duración que las tormentas ordinarias, tienen un alto grado de organización y están dotados de una rotación que, en ocasiones, propicia la formación de los devastadores tornados. Aunque la probabilidad de ocurrencia sea tan solo de un $10 \%$, el mero hecho de que algún grupo apunte en esa dirección debe ponernos en guardia (a los comunicadores), y hacernos valorar si damos a conocer ese dato a la audiencia. Con la incertidumbre cuantificada a nuestra disposición, deberíamos de hacerlo, teniendo cuidado de no crear alarma social. El objetivo que se persigue es advertir a la población para que esté prevenida y no le pille de sorpresa un fenómeno de alto impacto como esa posible supercélula, un viento huracanado, una inundación repentina o una intensa nevada.

La disponibilidad de grupos y supergrupos (sec. 27.4 en la página 406) construidos a partir de los SPC mejoraría notablemente la calidad no sólo de los pronósticos a medio plazo, de gran aceptación por parte de un amplio sector de la población, sino también en el corto plazo. Aunque con frecuencia es en el medio plazo donde aumenta sensiblemente la dispersión entre las salidas de los diferentes modelos deterministas, y entre los propios miembros de una predicción por conjuntos, en muchas situaciones delicadas, la dispersión puede ser importante también en el corto plazo. Volviendo al medio radiofónico y al programa en el que colaboro desde 2004 (el magacín de fin de semana de RNE «No es un día cualquiera», dirigido y presentado por la periodista PEPA FERNÁNDEZ), con frecuencia viajamos los fines de semana, habiendo emitido desde muchos lugares de España. Mi sección ( «El tiempo del tiempo») se emite los sábados y en ella ofrezco el pronóstico para el fin de semana en curso (sábado y domingo), así como un avance de predicción para la semana entrante. A veces, mi pronóstico a partir de D+3 es muy especulativo. Lo suelo confeccionar a partir del modelo determinista del Centro Europeo (ECHRES, sec. 19.2 en la página 291), cuya calidad objetiva lo sitúa entre los 4-5 mejores modelos del mundo pero que, a pesar de ello, se desvía de la evolución atmosférica real cuando la predecibilidad es baja. En estas situaciones es cuando más necesarias se vuelven las predicciones probabilistas, y cuando más se echan en falta, al no poder disponer de muchos de los productos.

Al final de la sección, Pepa me suele preguntar por el tiempo que se espera el siguiente fin de semana en el lugar desde donde está prevista la emisión del programa. Me está pidiendo un pronóstico local a 7 días vista. La mejor información que podría ofrecerle es la contenida en los meteogramas probabilistas del ECMWF. Cambiaría mis actuales comentarios del tipo «es pronto para saber si lloverá ese día», «todo apunta a que pasaremos frío»... por otros más preci- 
sos, que cuantificaran esa incertidumbre, para lo cual debería de buscarse una fórmula adecuada. Soltar una retahíla de datos porcentuales no parece la solución, por lo que habría que ir probando (método de pruebaerror) hasta dar con el discurso más acorde.

Para que ese progresivo cambio en la manera de comunicar el tiempo vaya materializándose, es necesario que los profesionales de la meteorología que trabajamos en los medios tengamos a nuestra disposición toda la batería de productos probabilistas existentes (mapas de probabilidades, meteogramas, supergru- pos...), sin restricción alguna para su difusión. La AEMET debería de ser el principal impulsor de esa apertura. Es necesaria una nueva política de datos a nivel europeo que permita la liberación de los productos probabilistas del ECMWF que a día de hoy todavía no se ha llevado a cabo. Desde AEMET sería igualmente deseable que se ofreciera formación y asesoramiento sobre su uso y sus características al colectivo de comunicadores meteorológicos, por tratarse de uno de sus principales usuarios. El reto probabilista está encima de la mesa no solo de los comunicadores, sino también de los Servicios Meteorológicos. 


\subsection{Comunicación de la probabili- dad y la incertidumbre en te- levisión}

\author{
MÓNICA LÓPEZ MOYANO \\ RTVE
}

Comunicar ¿qué es comunicar? Si echamos mano al Diccionario de la Real Academia de la Lengua Española nos encontramos con varias acepciones. Las dos primeras serían, probablemente, las que elegiría cualquier ciudadano para definir el verbo comunicar. Una sentencia que comunicar es «hacer a una persona partícipe de lo que se tiene» y la segunda apuesta por «descubrir, manifestar o hacer saber a alguien algo». La definición más correcta es la que ocupa el cuarto lugar, comunicar es «transmitir señales mediante un código común al emisor y al receptor». En esta frase encontramos reflejadas todas las etapas del proceso de comunicación.

El primer paso es el desarrollo de la idea: desarrollar la idea que se desea transmitir con determinada intención. Todos los hombres y mujeres del tiempo de los medios de comunicación en España, en mayor o menor medida, somos conscientes de la necesidad de hacer llegar al público la meteorología probabilista (cap 27 en la página 401). Entendemos que el futuro (y probablemente ya el presente) de la meteorología es abandonar la perspectiva determinista y dedicar todos los esfuerzos posibles en trasladar a la sociedad la probabilista. El desarrollo de la idea es, evidentemente, necesario para iniciar el proceso de comunicación, sin intención no tiene lugar.

El segundo paso es la codificación. La terminología utilizada que nos ocupa es uno de los principales escollos en este proceso de comunicación. La definición que hemos utilizado revela ese problema, el código debe ser común al emisor y al receptor. Por un lado, daremos por sentado que el emisor conoce y emplea correctamente ese lenguaje. Sin embargo, el conocimiento por parte del telespectador del lenguaje probabilista acostumbra a ser muy somero. De hecho, el principal problema que, a mi parecer, existe es que la terminología utilizada es de uso común. Es decir, las palabras probable y posible están en nuestro vocabulario cotidiano. El ciudadano entiende de forma natural que adjetivar con términos probabilistas implica incertidumbre, pero la mayoría, traduce incertidumbre en desconocimiento. «Es probable que vaya al cine» significa que tienes intención de ir, pero que no estás seguro. Incluso «es más probable que vaya al cine que, que no vaya y si voy, veré Cantando bajo la lluvia» me indica que si voy a la sala donde hoy reponen el clásico casi seguro que estás ahí, pero ambas expresiones me transmiten que no tienes claro que harás esta tarde.

En este sentido, en Televisión Española hemos optado por emitir de forma diaria los mapas de probabilidad (cap. 27.6.1 en la página 416) de precipitación (imagen de cabecera del capítulo) de la Agencia Estatal de Meteorología. Son mapas que nos sirven para mostrar cuán seguro puedes estar de que voy a ir al cine, pero no sabes qué película voy a ver. Entendemos que la repetición es la fórmula necesaria para hacer comprender los mecanismos de comprensión del lenguaje probabilista. Además los usamos todos los días, vaya a llover más o menos o nada, e insistimos en la diferencia: puede ser muy probable que llueva, pero puede llover muy poco.

La tercera etapa del proceso de comunicación es la transmisión. En este punto encontramos el vehículo de transmisión, que sería la televisión, y debemos intentar controlar las barreras y/o las interferencias. Tenemos que tener en cuenta que la televisión es un medio que consta de audio y vídeo, a diferencia de la radio, que es audio solamente y la prensa escrita, por ejemplo, que es solo imagen. La televisión tiene más ventajas aunque también son más los elementos a tener bajo control. Por un lado, los gráficos. Hay que elegir bien las escalas de colores, por ejemplo. Siguiendo con el caso de los mapas probabilistas de precipitación de AEMET. La escala de color va del verde claro (para probabilidades menores), pasando por el amarillo y acabando en el rojo (probabilidad más alta). A mi parecer, es una gama cromática acertada porque difiere mucho de la utilizada para la cantidad de precipitación, que usa la paleta de azules y acaba en violetas.

Por otro lado, en alguna ocasión especial, como puede ser un periodo de vacaciones concreto, Semana Santa o eventos meteorológicos extremos, hemos representado los supergrupos del Centro Europeo de Predicción a Medio Plazo también proporcionados por AEMET (sec. 27.4.2 en la página 409). En este caso, hemos utilizado directamente el porcentaje acompañando a la configuración atmosférica, para mostrar cuál de los escenarios futuros es el más probable. En este caso, consideramos que dicho producto nos da la posibilidad de dar grandes pasos en la difícil tarea de 
la divulgación. Enseñamos que hay una opción más probable que las otras, pero mostramos que existen opciones que no pueden ser descartables. Incluso, en algunas ocasiones, es una manera de mostrar al telespectador aquellos casos en los que la incertidumbre es muy alta y todas las posibilidades tienen un peso similar.

Evidentemente cuando tratamos de incorporar a nuestros espacios información de este estilo, previamente hacemos una reflexión profunda sobre qué contar y qué no. La comunicación científica eficaz, especialmente en medios de comunicación denominados «de masas», siempre está ubicada en una delgada línea entre lo que puede entender el ciudadano y el rigor científico.

Un último aspecto a tener en cuenta en el proceso de transmisión es el ruido. La televisión es un medio que se consume dentro de la actividad diaria. Es decir, un periódico se lee y requiere atención para leerlo. La televisión puede estar encendida en la cocina mientras cena la familia. Debemos contar con ello a la hora de elegir las palabras a utilizar, el tono o el volumen de nuestro discurso.

La siguiente etapa es la recepción. El receptor debe estar dispuesto a recibir el mensaje. El principal problema añadido al proceso de comunicación de variables con incertidumbre, que radica en el receptor, es el hecho de que el mensaje probabilista obliga al receptor a asumir la decisión. Usando la metáfora anterior, yo te digo qué probabilidad hay de que vaya a ver «Cantando bajo la lluvia» y cuál es la de que no vaya. Tú deberás decidir si te arriesgas a ir a la sala y ver a solas la película. En este sentido, entiendo que es una cuestión de tiempo que la sociedad se acostumbre a este tipo de información, que traslada el proceso de decisión, pero es más completa que la determinista.
El último paso significativo del proceso es el descifrado. Con él, la comunicación será exitosa, es decir, el receptor se hará una idea del mensaje que coincidirá con la que transmitió el emisor y de esta manera se habrá logrado la comprensión del mensaje original. En este paso volvemos a encontrarnos con la dificultad semántica. Es imprescindible que se incorpore dicho lenguaje a los procesos de aprendizaje del individuo. $\mathrm{Si}$ bien es cierto que los resultados de incorporar conocimiento en la cadena de enseñanza se obtienen a largo plazo, es inexorable la necesidad de hacerlo.

Finalmente, el primer punto del proceso de comunicación nos decía que la misma tiene sentido si detrás hay una intención. El proceso será completo si el receptor decodifica el mensaje, lo acepta y lo utiliza. La acción es el paso decisivo, se logra una acción como reacción del receptor al mensaje del emisor.

Todos los procesos de comunicación deben concluir con la retroalimentación. Es necesario cerrar el circuito. El receptor debería convertirse en emisor y establecer una interacción bilateral. De esta manera se consigue averiguar si el proceso se produce de forma correcta.

Nuestra experiencia es positiva, tanto con los mapas probabilistas como con los escenarios del Centro Europeo. Por ese motivo, nos alegra enormemente el proceso de apertura de ese tipo de información que ha iniciado la Agencia Estatal de Meteorología a través de su página web.

\subsection{Lecturas recomendadas}

Añadimos una serie de lecturas recomendadas que, aunque no estén referidas directamente, pueden completar los contenidos presentados en el capítulo: [9, $11,12,13,14,15,16]$. 


\subsection{Referencias}

[1] Abraham, Shymali y col. "Do locationspecific forecasts pose a new challenge for communicating uncertainty?" En: Meteorological Applications 22.3 (2015), páginas 554-562. DOI: 10.1002 /met . 1487 (citado en página 622).

[2] BECK, Ulrich. Risk society: Towards a new modernity. Volumen 17. Sage, 1992 (citado en página 616).

[3] Centro de Investigaciones SociolóGICAS. Percepción social de la ciencia y la tecnología. Informe técnico. 2006, página 7056 (citado en página 617).

[4] Centro de Investigaciones SociolóGICAS. Percepción de la meteorología. Informe técnico. Centro de Investigaciones Sociológicas, 2011, página 2959. URL: http: / / www . cis . es / cis / opencm / ES / 1 _ encuestas / estudios / ver . jsp? estudio $=12764$ (citado en páginas 618, 619).

[5] Crespo, Eduardo, Revilla, Juan Carlos y ElizaGa, Fermín. "Meteorología y sociedad: uso y evaluación de la información meteorológica/Meteorology and society: use and evaluation of meteorological information". En: Comunicación y Sociedad 27.2 (2014), página 169 (citado en páginas 617, 618, 621).

[6] Goffman, Erving. Frame analysis: An essay on the organization of experience. Harvard University Press, 1974 (citado en página 616).

[7] Joslyn, Susan y Savelli, Sonia. "Communicating forecast uncertainty: Public perception of weather forecast uncertainty". En: Meteorological Applications 17.2 (2010), páginas 180-195. DOI: $10.1002 /$ met . 190 (citado en página 617).

[8] Kahneman, Daniel y Tversky, Amos. "Choices, values, and frames". En: HANDBOOK OF THE FUNDAMENTALS OF FI-
NANCIAL DECISION MAKING: Part I. World Scientific, 2013, páginas 269-278 (citado en página 617).

[9] Kootval, H. "Guidelines on communicating forecast uncertainty". En: World Meteorological Organization/Technical Document 1422 (2008) (citado en página 626).

[10] KRUGer, Justin y Dunning, David. "Unskilled and unaware of it: how difficulties in recognizing one's own incompetence lead to inflated self-assessments." En: Journal of personality and social psychology 77.6 (1999), página 1121 (citado en página 616).

[11] Persson, Anders. "Los Meteorólogos no podemos escapar de las probabilidades". En: Tiempo y Clima 5.44 (2014), páginas 32-37 (citado en página 626).

[12] RAImONDI, Alessio. "Impacto social de la comunicación de las predicciones del tiempo". En: XXXI Jornadas Científicas de la $A M E$ (2010) (citado en página 626).

[13] Raimondi, Alessio. "La predicción, base cultural de la prevención". En: Tiempo y Clima 5.39 (2013), páginas 40-41 (citado en página 626).

[14] RAIMONDI, Alessio. "Utilidad social de las predicciones probabilísticas y su empleo en la historia de la meteorología". En: Prisma Social 12 (2014), páginas 45-88 (citado en página 626).

[15] RuIz, J. "Pronóstico probabilístico $\backslash$ ¿Por

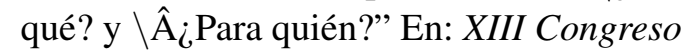
Latinoamericano e Ibérico de Meteorología (CLIMET) y X Congreso Argentino de Meteorólogos (CONGREMET), "Los desastres naturales y el cambio climático". 2009 (citado en página 626).

[16] ViÑAs, J. M. La comunicación de la ciencia del tiempo. 2012. URL: http: // naukas . com / 2012 / 12 / 22 / la-comunicacionde-la-ciencia-del-tiempo/ (visitado 26-11-2017) (citado en página 626). 